Portland State University

PDXScholar

\title{
The Correlation Between Specific Curiosity and Intelligence in Adults
}

Charles R. Schwenk

Portland State University

Follow this and additional works at: https://pdxscholar.library.pdx.edu/open_access_etds

Part of the Cognition and Perception Commons, and the Cognitive Psychology Commons Let us know how access to this document benefits you.

\section{Recommended Citation}

Schwenk, Charles R., "The Correlation Between Specific Curiosity and Intelligence in Adults" (1974). Dissertations and Theses. Paper 2164.

https://doi.org/10.15760/etd.2161

This Thesis is brought to you for free and open access. It has been accepted for inclusion in Dissertations and Theses by an authorized administrator of PDXScholar. Please contact us if we can make this document more accessible: pdxscholar@pdx.edu. 
AN ABSTRACT OF THE THESIS OF Charles R. Schwenk for the Master of Science in Psychology presented July 26, 1974.

Title: The Correlation between Specific Curiosity and Intelligence in Adults.

APPROVED BY MEMBERS OF THE THESIS COMMITTEE:
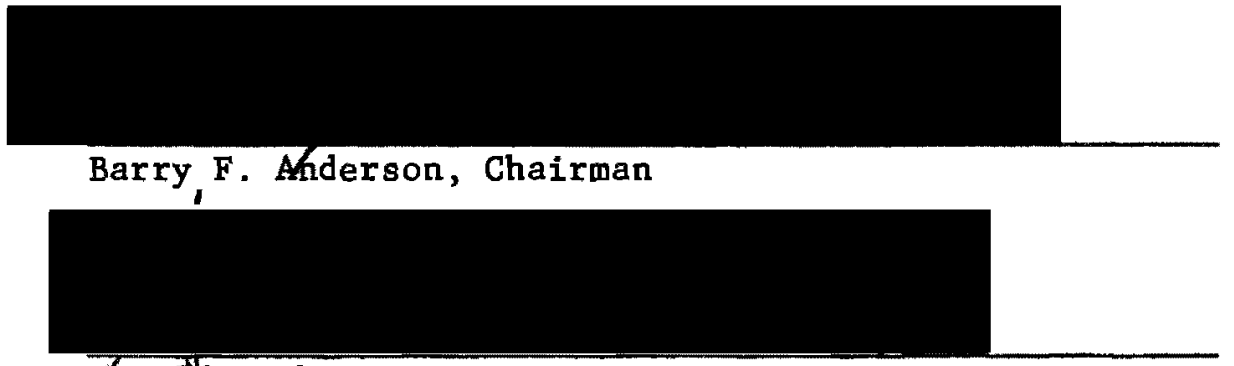

Gerald Guthrie

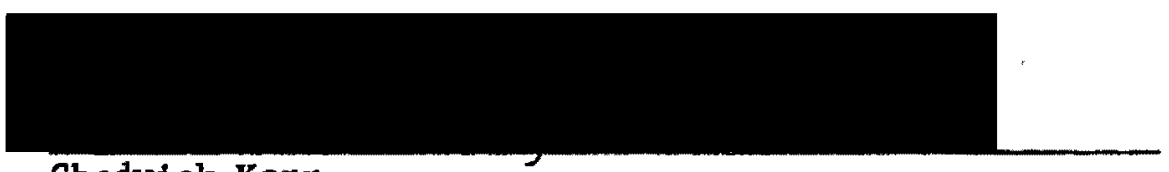

Chadwick Karr

Previous studies done on the correlation between specific curiosity and intelligence have been inconclusive. In the present study, a test of state specific curlosity and a test of intelligence were administered to

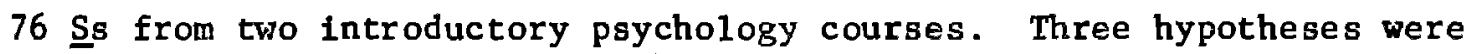
tested. These were, (a) that a significant specific curiosity-intelligence correlation would exist, (b) that the specific curiosity-verbal subscale correlation would be higher than the specific curiosity-abstraction subscale correlation, and (c) that there would be a sex difference in the specific curiosity-intelligence correlations. The data did not support 
hypothesis (a) or (b). However, they did support hypothesis (c). An inconsistent pattern of trends was discovered in the results which call the correlations into question. The suggestion was made that the study should be replicated. 
THE CORRELATION BETWEEN SPECIFIC CURIOSITY

AND INTELLIGENCE IN ADULTS

by

CHARLES R. SCHWENK

A thesis submitted in partial fulfillment of the requirements for the degree of

\section{MASTER OF SCIENCE}

in

PSYCHOLOGY

Portland State University

1974 
TO THE OFFICE OF GRADUATE STUDIES AND RESEARCH:

The members of the Committee approve the thesis of Charles R. Schwenk presented July 26, 1974.

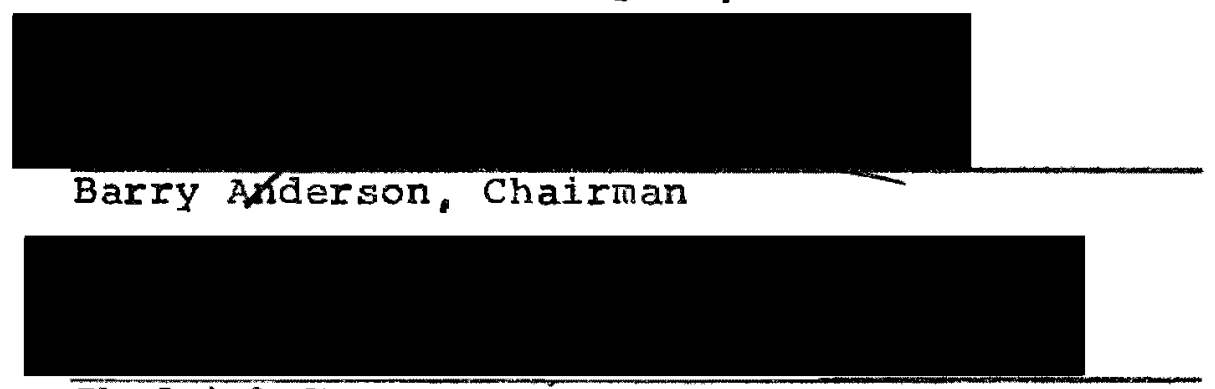

Chadwick Karr

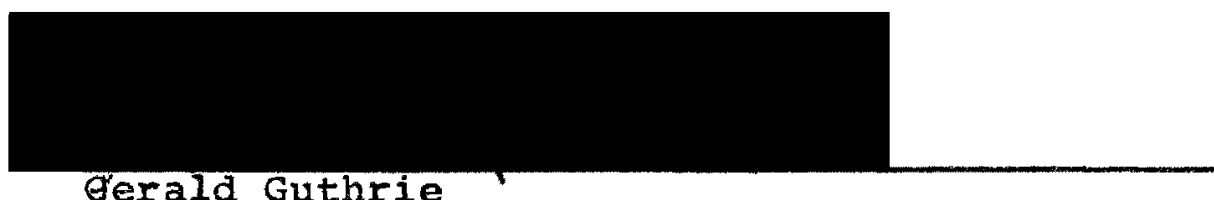

APPROVED :

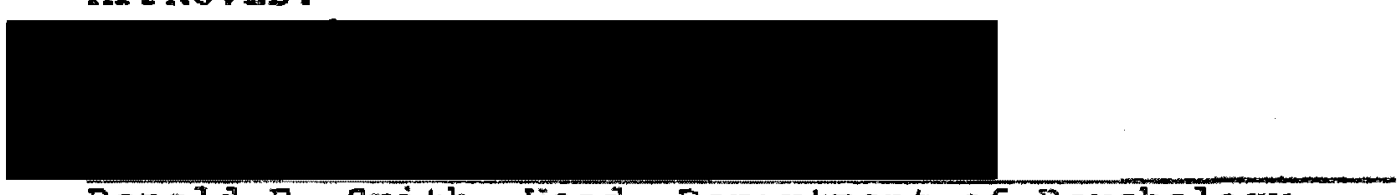

Ronald E..Smith, Fiead, Department of Psychology

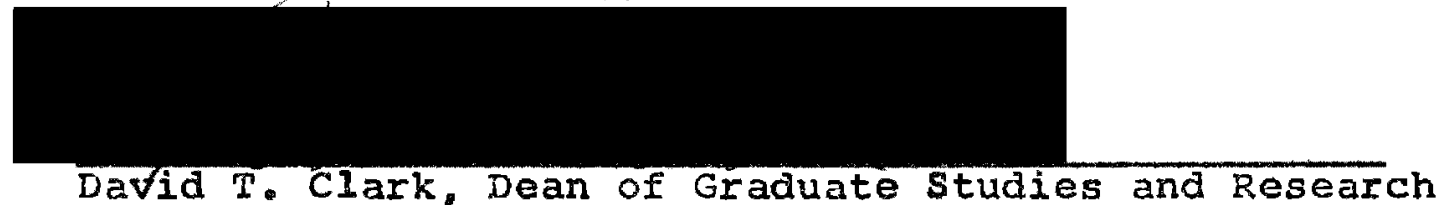

July 26,1974 
TABLE OF CONTENTS

PAGE

ACKNOWLEDGEMENTS . . . . . . . . . . . . . . . . . iv

LIST OF TABLES. . . . . . . . . . . . . . . . . . . vi vi

LIST OF FIGURES. . . . . . . . . . . . . . . . . . .vii

INTRODUCTION . . . . . . . . . . . . . . . 1

METHOD. . . . . . . . . . . . . . . . . 10

RESULTS. . . . . . . . . . . . . . . . 13

DISCUSSION. . . . . . . . . . . . . . . . . 16

REFERENCES. . . . . . . . . . . . . . . . . . 23 


\section{ACKNOWLEDGEMENTS}

First of a11, let me thank the members of my thesis committee, Dr. Karr, Dr. Guthrie, and Dr. Anderson, my Chairman. Dr. Guthrie helped me to develop the idea for my thesis and was very supportive and helpful during its completion. Dr. Karr showed a great deal of 1nterest in my topic and was also helpful in that he suggested several reference sources $I$ had not previously considered. Dr. Anderson spent a good deal of time with me and helped me considerably with analysis of my results. Of course all three of these people helped me in a number of other ways but I do want to keep this section short so I won't go into all of them but merely say thank you for all you did for me. You all were like good friends to me and helped make my stay in the Master's program a worthwhile experience.

Also, I would like to thank a few other people whose contributions were less extensive but no less essential. Dr. James Paulson provided me with some statistical tests which were essential to my analysis. Rolf Priebe ran my data through analysis on computer. Mrs. Doris Bennett typed the final draft of my thesis and did a beautiful job. Finally, Roger Dexter agreed to be the Graduate Council representative for my final oral and with his sparkling wit helped to transform it into more than just a simple final oral. 
These were the people who contributed most directly and obviously to the completion of my thesis. Thank you. I would also like to mention a much larger number of people who provided either support or inspiration in a less obvious way during my stay in the Master's program. These include Dave and Alice Duncan, Jill Melcher, my father C. C. Schwenk, J. S. Bach, Pauline and Raymond Hartbauer, Martin Luther, William James, Dr. Vance Eckstrom, Clive Lewis, Clark L. Hull, Rick Reynolds and Barbara Moschofsky (soon to be Mr. and Mrs. Rick Reynolds), Suzaki Roshi, Susan Harding, and of course, He for Whose glory we all exist. 


\section{LIST OF TABLES}

1. Means and Standard Deviations for Men and Women for Both Scales. . . . . . . . . . . . . . 13

2. Various Pearson Product Moment Correlation

Coefficients. . . . . . . . . . . . . . . . 13-14 
LIST OF FIGURES

\section{FIGURE}

PAGE

1. Eight-Cell Cube Representing The Possible Sorts

of Curiosity Scales. . . . . . . . . . . . . .

2. The Process by Which Curiosity Increases in Strength. ................ 18

3. The Same Flowchart Applied to the Drive of Hunger. . . . . . . . . . . . . . . . 18

4. Scattergrams of Curiosity-Intelligence

Correlations for Men and Women... . . . . . . . . 21-22 


\section{INTRODUCTION}

Day and Langevin (1969) have suggested that both Intelligence and curiosity are necessary for creative production in Individuals. A question which arises in relation to this statement is to what extent are the two traits, curiosity and intelligence, correlated. Measures of curlosity and intelligence.

The question is complicated by the fact that neither intelligence nor curiosity are unidimensional constructs. Curiosity may be divided according to three distinctions which are the perceptual vs. epistemic distinction, the specific vs. diversive distinction, and the trait vs. state distinction.

The perceptual-epistemic distinction was proposed by Berlyne (1965, pp. 244-254). According to him, perceptual curiosity is caused by an organism's incomplete perception of the stimulus field and leads to locomotor exploration of the physical environment. Epistemic curiosity, on the other hand, is caused by conflicting symbolic processes and is directed toward symbolic material. Thus, perceptual curiosity is related to the physical environment while epistemic curiosity is related to the symbolic environment.

The distinction between specific and diversive curiosity was made by H. I. Day (1969), and is based on a distinction made by Berlyne between specific and diversive exploration. Specific exploration is directed toward obtaining information from specific sources while diversive exploration is almed at getting information from a wide range of 
sources which might be entertaining or amusing (Berlyne, 1965, pp. 244-245). Thus, specific curiosity is a function of a need for a given kind of information while diversive curiosity is a function of time spent in a monotonous environment. This distinction has received experimental confirmation in a factor-analytic study by Langevin (1971).

The third distinction has to do with how curiosity is measured and was pointed out by Leherissay (1971). This is the distinction between measuring curiosity as a trait and measuring it as a drive state. Trait scales for curiosity tend to have high test-retest correlations and measure curiosity as a relatively invariant personality trait. State scales, on the other hand, measure curiosity as a drive :aroused by certain specific materials and do not have high test-retest correlations. Thus, the possible sorts of curiosity scales may be represented in an eight-cell cube as shown below.

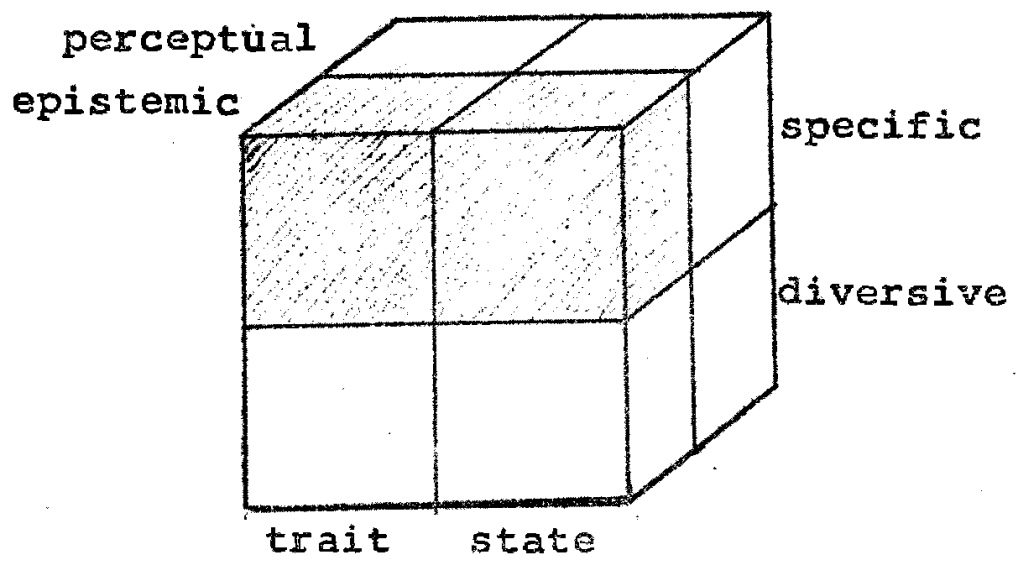

Figure 1. Eight-cell cube representing the possible sorts of curiosity scales. 
Henceforth, this paper will be dealing primarily with specific epistemic curiosity, both trait and state, as represented by the darkened blocks of the cube. The cited studies in the next section seem to indicate that it is this type of curiosity which correlates with intelligence (see pp. 5-6).

Intelligence is not a unidimensional construct either, and may be composed of as many as 120 factors (Guilford, 1967, pp. 60-66). There is a common division of this trait which appears on many IQ scales (Wechsler, Hartford-Shipley, California Test of Mental Maturity). It is the division into two subscales. The first is the verbal subscale and the second is thought to represent a non-verbal component or a component distinct from verbal ability. It is called the performance subscale on the Wechsler, the abstraction subscale on the Hartford-Shipley, and the non-verbal subscale on the CTMM.

It is reasonable to assume that a higher curiosity-intelligence correlation will exist for verbal subscales than for non-verbal subscales, particularly if the verbal subscales are composed of vocabulary items. This point will be discussed later in the paper. The theory which accounts for specific curiosity-intelligence correlations, Berlyne has described epistemic curiosity as a drive which is caused by an aversive cognitive state called conceptual conflict. Conceptual conflict was described as "conflict between incompatible symbolic response patterns, that is, beliefs, attitudes, thoughts, ideas" (Berlyne, 1965, P. 255). 
There are two likely ways of responding to this conflict. These are with curiosity and with anxiety. If the primary response is anxiety, all thoughts relating to the conflict may be supressed (Berlyne, 1965, pp. 259-260), and situations in which the conflict will occur may be avoided.

If the primary response is curiosity, however, the individual will seek information which will make one symbolic response pattern clearly preferable to the other and thus relieve the conflict. Further, the knowledge acquired in this way should lead to the preferable response or the symbolic response which is most reinforcing in terms of gaining a desired goal. Thus specific exploration is likely to be reinforced and the strength of the drive of specific curiosity is 1ikely to increase with the number of successful exploratory ventures.

If this explanation of the process is correct, people with higher intelligence should be more likely to have a stronger curiosity drive than those with lower intelligence. This is because people with higher intelligence would be more likely to get information they seek than people with low intelligence. Hence, they would be reinforced more often for specific exploration and would resort more to curlosity rather than supression or avoidance as a response to conceptual conflict.

If we examine the relationship between curiosity and IQ test scores, there is another basis for predicting a positive correlation between the scores. People with high specific curiosity should tend to learn more about each specific subject they study than people with low specific curiosity. The total of this increased learning of specific subjects would lead to a greater total amount of information possessed. Since 
general information is a subscale of some IQ tests like the Weschler, the effects of specific exploration would show up as higher scores on these subscales and a higher total IQ score. This might also hold true for general vocabulary scales, vocabulary being sensitive to the effects of exploratory activity. Thus, there are two mechanisms which would be likely to produce correlations between specific curiosity and IQ scale scores.

Curiosity-intelligence correlations in children.

Several studies have been done with children which deal with the questions I have raised. Most of these studies which deal with correlations between intelligence and curiosity fail to differentiate between the various possible dimensions of curiosity. When a study reports no correlation between scores on an IQ test and scores on a curiosity test, it is often not clear what sort of curiosity is being measured.

Richman (1972) compared normal and mentally retarded children by using a behavioral measure of curiosity which consisted of a forced choice situation in which each child had to choose either a box with an unknown object in it or a favorite toy. He found that retarded children choose the toy over the box significantly more often than normals. It appears that Richman was dealing with specific curiosity in this study but he did not specify which kind he intended to deal with.

H. I. Day (1968) developed a scale for specific curiosity based on interest in visual complexity and tested for a correlation between soores on this test and scores on the Dominion Group Test of Learning Capacity. He found no correlation. However, he also attempted to find a correlation between scores on his test and school grades. He found significant 
correlations with some school subjects which seem to have very little to do with curiosity of any kind. For example, the highest correlation was with penmanship. The conclusion which might be drawn is that Day's scale is not a valid measure of specific curiosity.

Maw and Maw (1965), in a study on personality variables differentiating high and low curiosity children found a low positive correlation between a curiosity score based on several different tneasures and scores on the Lorge-Thorndike IQ scale. The curiosity measures used were a teacher judgment of curiosity, a peer judgment, and a self judgment.

Fina11y, in a study by Langevin (1971) two different IQ scales, the otis and the Raven, and a number of curiosity scales, including the Test of Specific Curiosity, the Test of Reactive Curiosity, the Teacher Ratings of Curiosity, the Interest in Complexity lest, and the Experimenta1 Curiosity Test were used. No overall correlation between curiosity and intelligence was found. However, Langevin isolated two curiosity factors which correspond to specific and diversive curiosity. These were depth and breadth curiosity. Not all of his scales were of the same type. Some represented breadth and some depth curiosity. Similarly, not all the IQ scales he used correlated well with each other.

He did find high correlations between scales which measure specific curiosity (he called it depth) and the otis IQ scale. This supports the finding of the previously cited studies that IQ scores correlate with scores on specific curiosity scales. 


\section{Curiosity-intelligence correlations in adults.}

There are several interesting speculations which might be made about curiosity-intelligence correlations in adults. First, a significant correlation would be predicted. This correlation would be likely to be significant in spite of the fact that it is difficult to get a significant correlation in children across a normal IQ range. A strong correlation would be predicted on the basis of either of two mechanisms. First of all, by adulthood more time would have elapsed in which the bright people could have developed strong curiosity through reinforcement of their successful attempts to gain knowledge erom the environment. Also, by adulthood more time would have elapsed in which the curious people could have acquired the information which would show up on general information and vocabulary scales. Thus the process might be described in terms of a positive feedback loop; one in which higher intelligence leads to increased curiosity or one in which higher curiosity leads to increased intelligence. Specific curiosity-intelligence correlations should be a positively accelerating function of age.

Second, a higher specific curiosity-intelligence correlation for some IQ scales than for others would be predicted on the basis of the assumption that higher curiosity leads to higher IQ scores. This is because some subscales are likely to be more sensitive to the effects of exploratory activity than others. Vocabulary scales, for example, should correlate more highly than numerical reasoning scales.

Finally, a sex difference in specific curiosity-intelligence correlations would be predicted if we assume that women and men are 
reinforced differently for exploratory activity. It may be that only intelligent women are reinforced while all men are reinforced for exploration. This would lead to a different correlation for women than for men. A study by Maw and Maw (1965, p. 93) showed that a higher positive correlation between some measures of curiosity and the Lorge-Thorndike IQ scale existed for grade-school girls than for grade school boys. It may be that this difference also exists in adulthood.

An experiment was done by Day and Langevin (1969) which tested some of these predictions. They administered tests of intelligence, creativity, and curiosity to 75 female nursing students. The curiosity tests administered were two specific curiosity tests developed by Day. One was a perceptual test and the other was a questionnaire. Neither of them has had adequate validation. The intelligence test administered was the HartfordShipley Aptitude Test. The IQ scores for the group had a range of only 18 points, from 104 to 122 , with a mean of 116 . Though the two specific curiosity scales were supposed to measure the same construct, they did not correlate significantly with one another (r of . 19) and they did not have the same correlation with the intelligence test ( $r$ of .17 for the perceptual test and the IQ test and $r$ of .21 for the questionnaire and the IQ test) (Day and Langevin, 1969, p. 267).

The findings were that the total IQ score did not correlate significantly with either of the curiosity scales. However, both tests showed a significant correlation with the verbal subscale and a slight nonsignificant negative correlation with the abstraction subscale. This negative correlation would not be predicted and may be merely an artifact (Day and Langevin, 1969, P. 267). 
There are several methodological inadequacies in this study. These include sex restriction, IQ range restriction, occupational restriction, and the use of curiosity scales which were both called specific curiosity scales but have not been validated and do not correlate with each other.

The present study was in some ways a replication of Day and Langevin's study with the above-mentioned methodological inadequacies corrected. However, it also dealt with a question which was not asked in their study, that of possible sex differences in the correlation between specific curiosity and intelligence.

This study tested the three predictions previously made regarding specific curiosity-intelligence correlations: (a) that a strong specific curiosity-intelligence correlation will exist, (b) that higher correlations will exist for some IQ scales than others, and (c) that there will be a sex difference in the specific curiosity-intelligence correlation. The study compares relative performance on a test of curiosity and on an IQ test. 
METHOD

Scales used in the study.

The IQ test used was the Shipley Institute of Living Scale. This is a group test of intelligence which requires 20 to 25 minutes to administer. It yields a verbal (vocabulary) score, an abstraction score, and a total score for intelligence. It has a reliability of .92 and a correlation of .70 with the WAIS, which establishes its construct validity. Further, it has a correlation of .89 with the Otis (Shipley, 1949). It may be regarded as a good estimate of general intelligence (Buros, 1949, review no. 95 ; Buros; 1972 , review no. 138).

The specific curiosity scale was the Leherissey State Epistemic Curiosity scale which is actually a state specific-epistemic scale. This, in the author's estimation is the best curiosity scale which has been developed for adults. It is composed of 20 questions with four possible responses to each question. It asks for a student's curiosity responses to material he has been studying in class. For example, two of the questions read, "The material I learned was very interesting to me." and, "I would enjoy reading more about this subject matter." The four possible responses to each of the questions are: (1) not at a11, (2) somewhat, (3) moderately so, (4) very much so.

As to reliability and validity, the test has an alpha reliability of .89 which demonstrates its internal consistency, and more validation work has been done on this scale than on any other scale I have examined 
dealing with curiosity in adults (Zuckerman, 1964; Day 1969; Langevin, 1971). This scale has a correlation of .43 with a test of trait-specific curiosity, the Ontario Test of Intrinsic Motivation. Further, it has a near-zero correlation with the Zuckerman Sensation Seeking Scale which is considered a diversive curiosity scale (Leherissey, 1971). Leherissey, (1972) showed a negative correlation between state curiosity as measured by her scale and state anxiety which would be predicted on the basis of the curiosity theory I outlined on page 3 in which curiosity and anxiety are seen as two possible responses to new learning situations. Thus to the extent that anxiety is aroused in a learning situation curiosity should be inhibited. In another study, she showed a positive correlation between scores on her scale and amount learned in a computer-assisted.1earning situation, which would be predicted from the theory (Leherissey, 1972). Finally, Judd (1973) provided further validation for the scale in another computer-assisted learning situation. Thus the scale appears to have some degree of empirical validity.

Subjects.

I administered the Shipley and the Leherissey scales to two groups of undergraduates in two introductory psychology classes. These classes contained 57 and 19 Ss respectively for a total of 76 . There were 47 men and 29 women. The mean age for men was 21.5 years and for women it was 21.6 years. Procedure.

Each $\underline{S}$ was asked to indicate his or her sex by marking $\underline{M}$ or $\underline{E}$ on the test paper. Because I used groups of undergraduates in undergraduate 
psychology courses, I felt there might be a contaminating effect due to the fact that some of the $\underline{S}$ sere psychology majors and might have an interest in the course material which they would not have if they were not psychology majors. Therefore, each $\underline{S}$ was asked to indicate whether or not he was a psychology major. There were five psychology majors. 
RESULTS

TABLE I

MEANS AND STANDARD DEVLATIONS

FOR MEN AND WOMEN

FOR BOTH SCALES

Men

Women

IQ Scale:

mean

117

9.169

117

standard deviation

55.53

58.59

mean

6.909

7.419

TABLE II

VARIOUS PEARSON PRODUCT-MOMENT

CORREIATION COEFFICIENTS

\begin{tabular}{lll}
\multicolumn{1}{c}{ Correlation } & Value & $\mathrm{N}$ \\
\hline $\begin{array}{l}\text { Coriosity-intelligence } \\
\text { both sexes: }\end{array}$ & .1657 & 76 \\
$\begin{array}{l}\text { Curiosity-intelligence } \\
\text { men: }\end{array}$ & $.3652 * *$ \\
$\begin{array}{l}\text { Curiosity-intelligence } \\
\text { women: }\end{array}$ & & 47 \\
$\begin{array}{l}\text { Curiosity-verbal subscale } \\
\text { both sexes: }\end{array}$ & -.1822 & 29 \\
\end{tabular}




\section{Correlation}

Curiosity-abstraction subscale

both sexes:

Curiosity-intel1igence

Class 1:

Curiosity-intel1igence

class 2:

Curiosity-intel1igence

men, Class 1:

Curiosity-intelligence

men, Class 2:

Curiosity-intelligence

women, Class 1:

Curiosity-intelligence

women, Class 2:

Curiosity-verbal subscale

men:

Curiosity-abstraction subscale men:

Curiosity-verbal subscale women:

Curiosity-abstraction subscale women:

Curiosity-intelligence

psychology majors:
Value

N

.0723

76

.2131

57

$-.0246$

19

$.3938^{\star}$

34

.2101

13

$-.1226$

$-.3971$

6

$.4384 * *$

47

.2320

47

$-.1038$

29

. .2081

29

$-.0170$

5

*--significant at the .05 level

**--8ignificant at the .01 leve 1 
The Fisher $r$ to $Z$ transformation was used to test for a significant difference between the curiosity-verbal subscale correlation and the curiosity-abstraction subscale correlation for both sexes. The difference was not significant with a $\mathrm{z}$ value of 1.03 . The same test was used to test for the significance of the difference in specific curiosityintelligence correlations between men and women. This difference was found to be significant at the .01 level, with a $z$ value of 2.34 .

The difference between the specific curiosity-intelligence correlation for the psychology majors and that for the group as a whole was found to be non-significant with a $Z$ value of .259. The difference between class 1 and class 2 for these correlations was also found to be non-significant with a $\mathrm{Z}$ value of .905 .

A t-test for the significance of the difference of the means of the curiosity test for men and women showed no significant difference with a $t$ value of 1.82 . An F-test for the significance of the difference between the variances for men and women on the curiosity test also showed no significant difference, with an $F$ value of .5356 . There was also no significant interaction between sex and verbal subscale-curiosity correlation or abstraction subscale-curiosity correlation. 


\section{DISCUSSION}

The first hypothesis to be tested, that there should be a significant correlation between the scores on the curiosity test and the scores on the IQ test, was unsupported by the data. While the obtained correlation (.1657) was in the predicted direction, it was not significant. The finding of a non-significant correlation between specific curiosity and intelligence is in agreement with the findings of Day and Langevin (1969) and some of the studies with children comparing intelligence with various types of curiosity (Day, 1968; and Langevin, 1971). However, the fact that a significant positive correlation was obtained for men and a non-significant negative one was obtained for women gives this overall result a new significance. It appears that the overall non-significant result may be due to averaging a positive one with a non-significant or negative one. This difference in correlation between men and women may help to account for the lack of significant overall correlations in the previously cited studies which pooled males and females.

The second hypothesis, that there should be a significant difference between the specific curiosity-verbal subscale correlation and the specific curiosity-abstraction subscale correlation for both sexes was unsupported by the data. The analysis also revealed that there was no significant difference for the men alone or the women alone in these correlations. However, for both sexes individually the correlation between specific 
curiosity and the verbal subscale was higher than the correlation between specific curiosity and the abstraction subscale. This trend is in the direction which would be predicted on the basis of the curiosity theory outlined on pages 2-4 and on the basis of Day and Langevin's (1969) results.

The hypothesis that there should be a significant difference between men and women in the overall correlation between curiosity and intelligence was supported by the data. The difference between men and women in the correlation was significant at the .01 level, with men having a significantly higher correlation. It appears that sex is an important moderator variable in specific curiosity-intelligence correlations. Mischel (1971, pp. 149-150) has suggested that it may be an Important moderator variable In a wide range of correlations between different measures.

This result contradicts the result which Maw and Maw found in their study with grade-school children in which a higher correlation was found for girls than for boys (Maw and Maw, 1965). One possible explanation for this is that reinforcement contingencies may change with age. In childhood it may be that intelligent girls are reinforced for curiosity regardIng school subjects while boys are not. By college age, however, it may be that only the intelligent men are reinforced while women are not differentially reinforced for specific curiosity.

The theory of curiosity previously outlined suggests two basic reasons that a difference in the specific curiosity-intelligence correlation should appear between men and women. The process by which curiosity increases in strength can be represented in the following flowchart: 
curiosity $\rightarrow$ information $\longrightarrow$ reinforcement

Figure 2. The process by which curiosity increases in strength.

The intelligent individual is thought to be more successful in obtaining information which he is curious about and more successful in using that information to obtain reinforcement.

This mechanism would admittedly not be applicable to all drives, especially primary ones. For example, the flowchart applied to the drive of hunger would look like this:

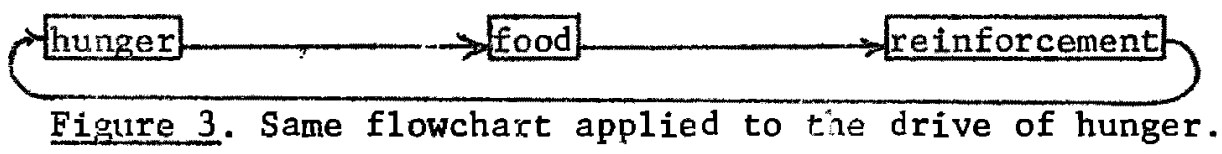

Here, hunger would lead to food which would be reinforcing and lead to increased hunger. The drive of hunger operates in the opposite way. It increases in strength when it is not followed by food and decreases in strength when it is followed by food. However, the drive of curiosity is a second order drive and, according to the theory developed by Berlyne and others (Berlyne, 1965), increases in strength in general because it is seen to lead to information which is reinforcing in several ways. Regarding the difference between men and women in this correlation, two hypotheses may be drawn from the flowchart as possible explanations. The first is that one sex may be less successful than the other in obtaining information. If the overall intelligence of both sexes is the same, as it was in this sample, it seems likely that the difference is not due to the lesser ability of one sex to obtain information but to some other 
factor. Second, it may be that both sexes are equally successful in obtaining information but that information has different reinforcement value for each sex. Here, it may be that information is intrinsically rewarding or that the reward comes primarily from extrinsic factors. In either case, the reward value could be different for men and women.

Looking at the means and standard deviations for men and women on the specific curlosity scale it can be seen that while there is no significant difference between them, both mean and standard deviation are higher for women than for men. It is assumed on the basis of the theory of curiosity previously outlined that reinforcement of successful exploratory behavior will cause curiosity to increase. Considering this assumption, and the higher mean curiosity score for women than for men, it is unlikely that women receive less reinforcement for specific curiosity than do men. If they did, their mean curiosity score should be lower than the mens'. The simplest explanation which accounts for both the higher specific curlosity-intelligence correlation for men and the higher mean curiosity score for women is that women either have greater access to information or receive more reinforcement overall but that the reinforcement is not differentiated between high and low inteligence as much as it is in men. In other words, in women it may be that both those of high intelligence and those of low intelligence are reinforced for specific curiosity. In the context of the classes from which this data was drawn, it may be that the intelligent women were reinforced in terms of social approval for exploring material presentea in class because they could master it. Conversely, the less intelligent women may have been reinforced 
in some way for curiosity about material which they had difficulty mastering. On the other hand, perhaps only intelligent men are reinforced for curiosity about the sort of material presented in the classes. Less intelligent men may have been punished in some way for curlosity, It may have been, for example, that social pressure was applied by family and friends on intelligent men to stay in school and study the material they were presented with and be curious about it while pressure from similar sources was applied to the less intelligent men to be less interested in and curious about the material and perhaps to drop out of school. This explanation would account for both the mean difference and the correlation difference.

If these explanations are correct, a greater percentage of men than women would be expected to be both 10 w In IQ and low in curiosity. Scattergrans for both men and women have been included (see next 2 pages) but there were too few subfects to be able to detect a clear pattern from them.

More revealing are the variances for men and women on the curiosity scale. The variance for women is larger than the variance for men though this difference is not significant. This difference represents a trend in one direction. However, if the explanation fust proposed to account for the difference in correlations and the difference in means is correct, a larger variance for men than for women would be predicted. If women were reinforced undifferentially, then it would be predicted that this reinforcement would tend to push the curiosity scores for the less intelligent wonen closer toward the scores for the more intelligent ones. 
MEN

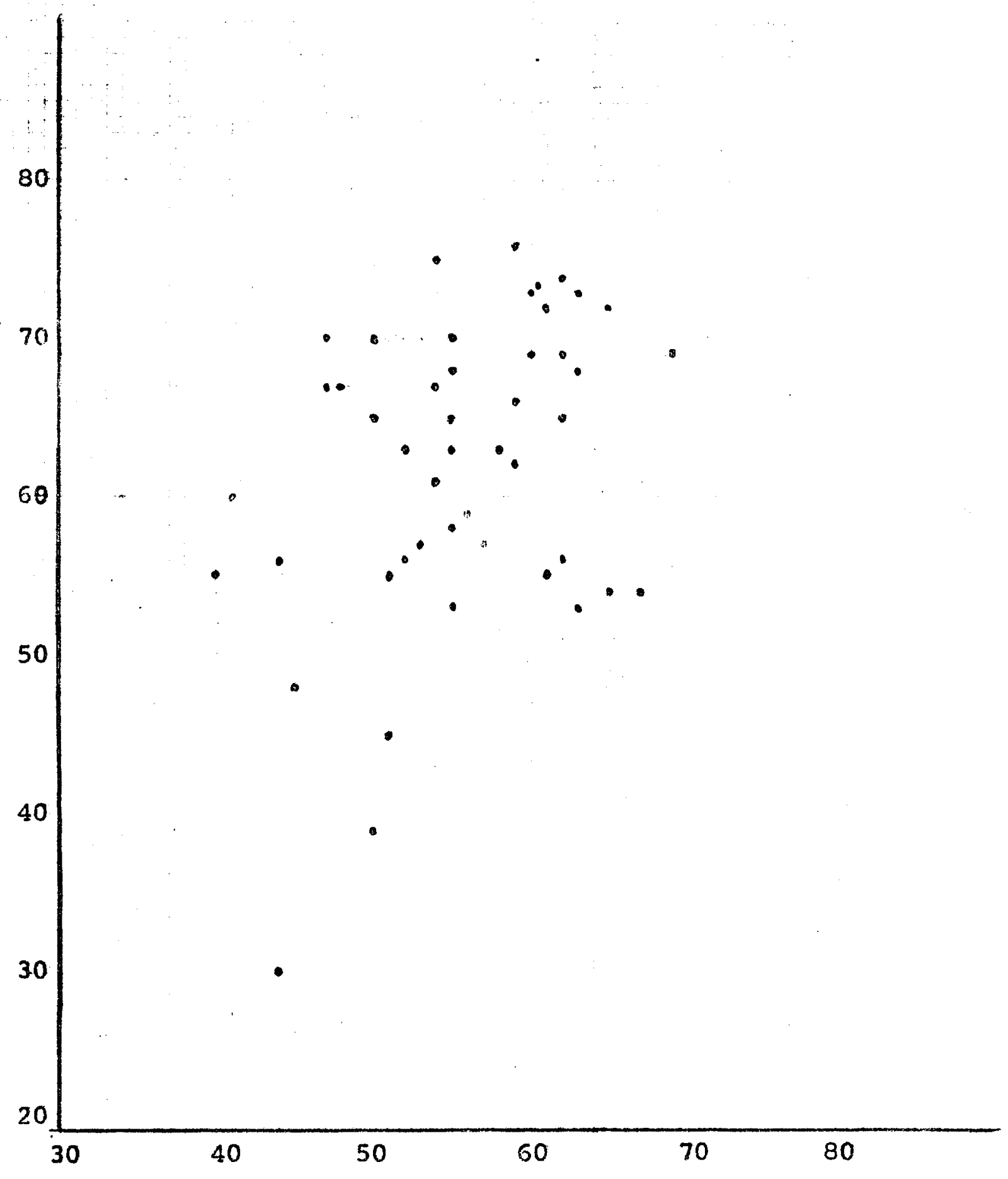


WOMEN

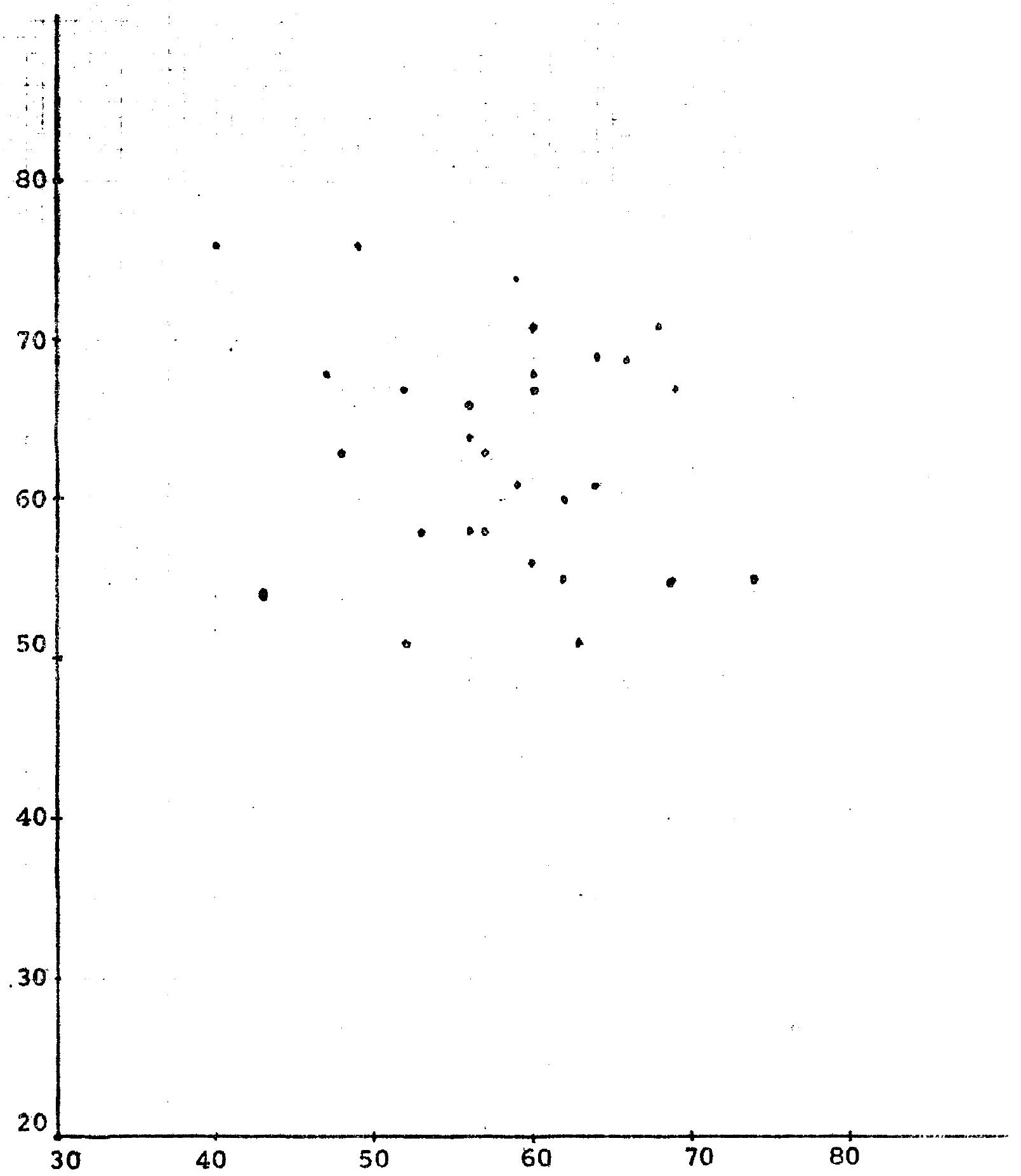


There are three possible explanations which might be offered to explain this inconsistency; (a) that there is another explanation, more complex than the one previously offered, which will account for the results, (b) that one of the results is artifactual, probably the difference between the variances since it is least nearly significant, or (c) that scores on the curiosity scale may have been influenced by social desirability.

Regarding explanation (a), it might be possible to develop a more complex explanation than the one already shown to be insufficient. One possible explanation would be that there is another moderator variable which correlates with curiosity in women besides intelligence. Such a variable might be skill in social interactions. Thus we would assume that intelligence is not tied to curiosity in the same way for both men and women. Therefore the higher variance on the curiosity scale for women would not present a stumbling block because we are not dealing with the same process of reinforcement in the same moderator variables for both sexes. There are a number of possible alternate explanations which might account for the apparently contradictory results obtained. However, in view of the fact that neither the difference between the means nor the difference between the variances is significant, it would seem reasonable to administer the tests again under similar circumstances to determine whether either of these differences is artifactual before considering alternate hypotheses.

As to explanation (b), it may be that one of the results was artifactual. However, it would not be safe to merely assume that a given one of the results, say the variance, is artifactual and proceed with an 
explanation on the basis of this assumption. Rather, the proper course of action would be to administer the tests again under similar circumstances to determine which of the results is artifactual.

Regarding explanation (c), if the scores on the curiosity scale are influenced by the social desirability of some of the items and the women respond differently than the men to socially desirable items, this might account for the mean difference in the scores on the curiosity scale for men and women.

The most reasonable procedure under these circumstances would seem to be to administer the tests again undex similar test conditions to another group of $\underline{S}$ s and include a social desirability scale. The results could then be examined to determine whether the seemingly inconsistent pattern is artifactual and whether scores on the social desirability scale correlate with scores on the curiosity scale. 


\section{REFERENCES}

Berlyne, D. E. A theory of human curiosity. British Journal of Psychology, 1954, 45, 180-191.

Berlyne, D. E. Structure and Direction in Thinking. New York: John Wiley and Sons, 1965.

Buros, O. K. (Ed.) The Mental Measurements Yearbooks. Highland Park, N. J.: Gryphon Press, $1949 \& 1972$.

Day, H. I. A curious approach to creativity. Canadian Psychologist, 1968 9, 485-497.

Day, H. I. The role of specific curiosity in school achievement. Journal of Educational Psychology, 1968, 58, 37-43.

Day, H. I. A progress report on the development of a test for curiosity. A paper read at the 1969 National Seminar on Adult Education Research. Feb. 10, 1969, Toronto.

Day, H. I. and Langevin, R. Curiosity and intelligence: Two necessary conditions for a high level of creativity. Journal of Special Education, $1969,3,263-368$.

Guilford, J. P. The Nature of Human Intelligence, New York: McGraw-Hi11, 1967.

Hays, W. I. Statistics for the Social Sciences, New York: Holt, Rinehart, and Winston, Inc., 1973.

Judd, W. A. Further validation of a state epistemic curiosity measure in computer-managed instruction. Proceedings of the 81st Convention of the American Psychological Association, 1973, 8 621-622. 
Langevin, R. Is curiosity a unitary construct? Canadian Journal of Paychology, 1971, 25. 360-374.

Langevin, R. I. A study of curiosity, Intelligence, and creativity. D1ssertation Abstracts, 1972, 32, 6207.

Leherissey, B. L. Development of a measure of state epistemic curiosity. GAI Center Technical Report: Florida state Univarsity,

- Technicai Yemo' no. 34, 1971.

Leherissey, B. L. Bffects of stimulating state epistemic curiosity on state anxiety and performance in a complex computer-assisted learning task. Proceedingis of the goth Convention of the American Paychological Association, 1972; I, 501-502.

Leher1ssey, B. L. Validation of a masure of state eplstemic curlosity In a computer-assisted learning situation. Proceedinge of the 80th Convention of the American Paychological Areociation. 1972, I, 523-524.

Maw, W. H. and Maw, E. W. Personal and social varlables differentiating children with high and low curiosity. Cooperative research project no. 1511, U. S. Department of Health, Education and Welfare, 1965.

Maw, W. H. and Maw, E. W. Differences between high and low curlosity fifth graders in recognition of verbal absurdities. Journal of Educational Psychology, 1972, 63, 558-562.

Mischel, W. Introduction to Personality. New York: Holt, Rinehart, and Wiaston, Inc. 1971. 
Richman, C. L. et al. Curiosity behavior in normal and mentally retarded children. Psychonomic Science, 1972, 29, 212.

Roscoe, J. T. Fundamental Research Statistics for the Behavioral

Sclences, New York: Holt, Rinehart, and Winston, Inc., 1969.

Shipley, W. C. A self-administering scale for measuring intellectual impairment and deterioration. Journal of Psychology, 1940, 9 , $371-377$.

Suckerman, M. et al. Development of a sensation seeking scale.

Journal of Consulting Psychology, 1963, 28, 477-482. 